ORIGINAL ARTICLE

\title{
Reexamining construct validity of the Short Dark Triad (SD3) scale
}

\author{
Nasrina Siddiqi (DD) $1 \cdot A, B, C, D, E, F$, Mohammad Ghazi Shahnawaz ${ }^{2 \cdot A, B, C, D, E}$, Shagufta Nasir (D) $^{3} \cdot A, B$ \\ 1: Kamala Nehru College, University of Delhi, New Delhi, India \\ 2: Jamia Millia Islamia, New Delhi, India \\ 3: Institute of Human Behaviour and Allied Sciences, Delhi, India
}

\section{BACKGROUND}

The conceptualization of negative personality has evolved over the last few decades but the scientific assessment of negative traits is still at a nascent stage. The present study aimed to test the construct and external validity of the Short Dark Triad (SD3) scale, one of the most widely used scales to measure the dark triad, by conducting three independent studies.

PARTICIPANTS AND PROCEDURE

Exploratory factor analysis (EFA) was conducted on 379 participants and confirmatory bifactor analysis was carried out on a sample of 414 participants. Additionally, an independent sample of 168 participants was used to test the external validity of SD3.

\section{RESULTS}

In study 1, after the triarchic model was disconfirmed by a confirmatory factor analysis (CFA), an EFA was run on the original 27-item scale, which produced a two-factor model consisting of a dark dyad and narcissism. This was followed by a confirmatory bifactor analysis in study 2, which revealed that while Machiavellianism and psychopathy are better measured as manifestations of a general negative disposition, narcissism emerges as a distinct trait which is not significantly captured by the dark core of personality. Moreover, study 3 revealed that dark dyad is a better correlate and predictor of negative traits as compared to narcissism.

\section{CONCLUSIONS}

In keeping with these findings, we propose that narcissism should be measured holistically with equal emphasis on all its constituents and facets and that the intrinsic dimensionality of these traits must be captured while scoring. Implications and future directions are duly discussed.

\section{KEY WORDS}

validation; CFA; dark triad; EFA; bifactor analysis

Corresponding Author - Nasrina Siddiqi, Ph.D., Kamala Nehru College, University of Delhi, August Kranti Marg, New Delhi 110049, India, e-mail: mshahnawaz@jmi.ac.in

AUthors' CONTRIBUtion - A: Study design · B: Data collection · C: Statistical analysis · D: Data interpretation ·

E: Manuscript preparation · F: Literature search · G: Funds collection

to Cite this ARTICLE - Siddiqi, N., Shahnawaz, M. G., \& Nasir, S. (2020). Reexamining construct validity of the Short

Dark Triad (SD3) scale. Current Issues in Personality Psychology, 8(1), 18-30.

RECEIVED 30.12.2019 • REVIEWED 06.03.2020 • ACCEPTED 11.03.2020 • PUBLISHED 30.03.2020 


\section{BACKGROUND}

Over the last few decades, the notion of negative personality traits has undergone numerous conceptual modifications. Various frameworks of negative personality have attempted to identify specific traits that prompt people to defy ethics and morality. The most prominent of these is the dark triad model which proposes that negative personality consists of three core traits, viz. Machiavellianism, narcissism, and psychopathy. While Machiavellianism refers to manipulative personality, narcissism is described as having a sense of grandiosity, entitlement, dominance, as well as superiority, and psychopathy is characterized by high impulsivity and thrill-seeking along with low empathy and anxiety (Paulhus \& Williams, 2002). According to Paulhus and Williams (2002), dark triad is a term used to describe "a constellation of three socially undesirable but empirically overlapping personality traits".

Before this conceptualization, the three negative traits were considered as exclusive and independent (Jones \& Paulhus, 2014). However, later empirical studies (Jonason, Li, Webster, \& Schmitt, 2009; Jonason \& Kavanagh, 2010) found significant overlap, which led to the development of a second-order construct, viz. the dark triad (Jonason et al., 2009), as these traits share the same behavioral dispositions such as social aversion, self-promotion, and emotional coldness (Paulhus \& Williams, 2002). Moreover, Moshagen, Hilbig, and Zettler (2018) have explained this overlap in terms of a core dark personality disposition (D) from which the dark triad and other negative traits originate.

The dark triad has many negative and positive implications. It is strongly associated with increased sexual success (Jonason et al., 2009), sexual attractiveness (Carter, Campbell, \& Muncer, 2013) and mate retention (Jonason, Li, \& Buss, 2010). Dark traits have also been found to be strong predictors of leadership ability (Furtner, Maran, \& Rauthmann, 2017), career success (Spurk, Keller, \& Hirschi, 2015), political extremism, conservativism (Jonason, 2014), social dominance orientation (Jones \& Figueredo, 2013) as well as prejudice and discrimination (Sidanius \& Pratto, 1999). Given its importance in many domains of life, measurement of the dark triad is a serious concern. The present paper is a modest attempt in this direction.

Before the development of a psychometric tool to assess the three traits together, Jonason et al. (2009) first computed a composite dark triad score by converting the raw scores on three distinct measures of Machiavellianism, narcissism, and psychopathy into standardized $z$-scores. Using the same technique, Jonason, Li, and Buss (2010) provided empirical evidence suggesting that the dark triad, as a composite measure, could explain more than $50 \%$ of variance related to each of the three scales measuring its constituent traits. Put simply, measuring the three negative traits compositely turned out to be statistically more meaningful than assessing them separately. This finding led to the development of many psychological scales to assess the dark triad.

Jonason and Webster (2010) developed the Dirty Dozen scale that could produce cumulative dark triad scores. Although some researchers have documented satisfactory internal consistency and reliability (Czarna, Jonason, Dufner, \& Kossowska, 2016) along with appropriate validity indices (Maples, Lamkin, \& Miller, 2014), others have criticized the tool for its low incremental, discriminant, convergent and construct validity (Jones \& Paulhus, 2014). Kajonius, Persson, Rosenberg, and Garcia (2016, p. 1) have even accused this tool of "mismeasurement" of the dark triad due to its several limitations including the bimodal distribution of scores and low discriminatory power of narcissism items. To overcome some of these limitations, Jones and Paulhus (2014) developed a short dark triad scale known as SD3 and it was found to be more comprehensive than the former measure (Malesza, Ostaszewski, Büchner, \& Kaczmarek, 2019). SD3 has been found to possess satisfactory internal consistency (Jones \& Paulhus, 2014) along with convergent and discriminant validity (Pechorro et al., 2019). It has been translated into several languages and is used effectively across cultures (Gamache, Savard, \& Maheux-Caron, 2017; Salessi \& Omar, 2018; Malesza et al., 2019). Moreover, there are various parallel versions of SD3 (Atari \& Chegeni, 2016; Özsoy, Rauthmann, Jonason, \& Ardiç, 2017; Pechorro et al., 2019), which have been developed to suit specific populations. With its extensive use, SD3 is among the most widely employed tools for the measurement of negative personality traits (as per the number of citations) ${ }^{1}$.

Despite its popularity, many subsequent validation studies have questioned the psychometric properties of SD3 (Rogoza \& Cieciuch, 2017). The tool has been challenged primarily on two grounds. Firstly, SD3 fails to measure narcissism holistically. Narcissism is a layered construct with various cognitive and behavioral undertones. It has been described in several different ways. According to Kernberg (1998), narcissism involves a sense of superiority, grandiosity, and selfabsorption, along with exhibitionism, envy, exploitativeness, and mood instability. Similarly, Pincus and Lukowitsky (2010) contended that narcissism can be manifested either through grandiosity or vulnerability. They defined grandiosity in terms of arrogance, exhibitionism, entitlement and inflated self-esteem, whereas the aspect of vulnerability is characterized by a fragile self-esteem and emotional instability. Furthermore, the trifurcated model (Crowe, Lynam, Campbell, \& Miller, 2019) asserts that both these aspects of narcissism have a common core of antagonism that involves hostile and manipulative behavior.While SD3 effectively taps manipulative behavior, it sidelines behavior characterized by hostility. Research has confirmed that SD3 measures only grandiose narcissism 
and ignores the 'vulnerability' facet of the construct (Maples et al., 2014; Maharana, 2019). Moreover, SD3 is also incapable of distinguishing between psychopathy and Machiavellianism (Miller, Hyatt, Maples-Keller, Carter, \& Lynam, 2017). The failure to differentiate between these two traits consequently produces a twofactor model, i.e. psychopathy and Machiavellianism as one factor and narcissism as the second one (Persson, Kajonius, \& Garcia, 2017). Similar findings were obtained by Rogoza and Cieciuch (2017), who discovered that SD3 yields a two-factor model comprising of narcissistic grandiosity and the dark dyad. It is evident that SD3 has yielded inconsistent factor structures across studies; therefore its construct validity needs to be reexamined. Moreover, most of the aforementioned validation studies have been conducted in the Western world. Therefore, it is even more important to explore the dimensionality and psychometric attributes and not psychometric characteristics of SD3 in a non-Western context, if SD3 has to attain the status of a gold standard measure of the dark triad (Persson et al., 2017). The present research attempts to achieve this objective by conducting three studies.

Table 1

Model fit indices for SD3, obtained through CFA $(N=827)$

\begin{tabular}{lccc}
\hline Fit indices & $\begin{array}{c}\text { Obtained } \\
\text { values }\end{array}$ & $\begin{array}{c}\text { Cut off for } \\
\text { good fit }\end{array}$ & $\begin{array}{c}\text { Model } \\
\text { fitness }\end{array}$ \\
\hline CFI & 0.569 & $\geq 0.90$ & $\boldsymbol{x}$ \\
$\mathrm{GFI}$ & 0.888 & $\geq 0.95$ & $\mathbf{x}$ \\
$\mathrm{AGFI}$ & 0.869 & $\geq 0.90$ & $\mathbf{x}$ \\
$\mathrm{CMIN} / d f$ & 4.365 & $<3.00$ & $\mathbf{x}$ \\
RMSEA & 0.064 & $<0.08$ & $\checkmark$ \\
\hline Note Cut-off value source: Hair Black, Babin, and Anderson (2010).
\end{tabular}

\section{STUDY 1}

Study 1 was carried out with the objective of investigating whether SD3 fits the triarchic model of negative personality on which it is supposedly based.

\section{METHOD}

In the initial phase of study 1 , a confirmatory factor analysis, in AMOS (21), was carried out on the original SD3, using a sample of $N=827$ participants. These participants included both male $(n=490)$ and female ( $n=337)$ Indian college students from Delhi and National Capital Region of Delhi, India. They were in the age bracket of 18 to 21 years and the average age of the sample was 19.8 years.

\section{MEASUREMENT}

Data was collected using the original English version of the Short Dark Triad (SD3), developed by Jones and Paulhus (2014). The scale measures Machiavellianism, narcissism and psychopathy with a total of 27 items (i.e. 9 items per trait). Responses on the scale are recorded on a five-point Likert scale ranging from 1 (disagree strongly) to 5 (agree strongly) and there are five reverse scored items in the scale.

As can be seen in Tables 1 and 2 respectively, most of the fit indices as well as some of the factor loadings obtained through CFA were below acceptable levels (Hair, Black, Babin, \& Anderson, 2010). In order to obtain a superior model, some factors items with high covariance (as per modification indices) were co-varied and certain other items with extremely low factor loadings were deleted. However, the fit indices did not exhibit any significant improvement. Thereafter, a bifactor model was run on the same dataset which

Table 2

Factor loadings for SD3, obtained through CFA $(N=827)$

\begin{tabular}{lccccc}
\hline Items & Estimate & Items & Estimate & Items & Estimate \\
\hline Mach1 & 0.057 & Nar1 & 0.479 & Psy1 & 0.570 \\
Mach2 & 0.538 & Nar2 & -0.110 & Psy2 & -0.029 \\
Mach3 & 0.623 & Nar3 & 0.494 & Psy3 & 0.607 \\
Mach4 & 0.553 & Nar4 & 0.543 & Psy4 & 0.546 \\
Mach5 & 0.724 & Nar5 & 0.575 & Psy5 & 0.400 \\
Mach6 & 0.603 & Nar6 & -0.103 & Psy6 & 0.547 \\
Mach7 & 0.392 & Nar7 & 0.488 & Psy7 & -0.016 \\
Mach8 & 0.474 & Nar8 & 0.036 & Psy8 & 0.481 \\
Mach9 & 0.702 & Nar9 & 0.689 & Psy9 & 0.733 \\
\hline
\end{tabular}


too yielded fit indices $(\mathrm{CFI}=0.751$, TLI $=0.706)$ and loadings that were below the acceptable threshold. Therefore, an exploratory factor analysis was carried out, as suggested by Reis and Judd (2000): "If a specified CFA model fits poorly, subsequent EFA analyses might suggest alternative models or reasons why the model had poor fit” (p. 419).

For this purpose, two random samples were generated by SPSS from the original data set of 827 participants. The first dataset $(N=379$ with $n=230$ males and $n=149$ females) was used for EFA while the second one was utilized for confirmatory bifactor analysis in study $2(N=414)$.

\section{PRELIMINARY DATA ANALYSIS}

Prior to the analysis, data were checked for normality, missing values, and outliers, using SPSS 21 . No missing values or major outliers were found in the dataset. With regards to sample distribution, the results of the Shapiro-Wilk test revealed that the data lacked normality. However, no attempts were made to transform data as Tabachnick and Fidell (2007) have proposed that: "As long as principal component analysis or factor analysis are used descriptively as convenient ways to summarize the relationships in a large set of observed variables, assumptions regarding the distributions of the variables are not in force. However, multivariate normality is assumed when statistical inference is used to determine the number of factors" (p. 618).

In line with these guidelines, multivariate normality was tested using normal Q-Q plots, which indicated satisfactory multivariate normality. Afterwards, the KMO and Bartlett's values were examined to ensure sampling adequacy. The KMO value was 0.74 and Bartlett's test of sphericity also turned out to be significant $(p<.05)$, indicating that the data were adequate for factor analysis. Subsequently, the scree plot (Figure 1) was checked, which indicated that all 27 items could be grouped into 3 factors.

In the second run of analysis, the number of factors was set to 3 and the principal axis factoring method of extraction was used with Promax rotation. The obtained factor loadings ranged from .001 to .597 (Table 3).

Items with factor loadings less than 0.4 were deleted one by one in increasing order of factor loadings and factor analyses were run several times to get a simple structure (Maskey, Fei, \& Nguyen, 2018). Maskey et al. (2018), in a review of 35 EFA based studies, found that a factor loading of 0.4 is widely taken as a cut-off value in such studies (Cerit, 2000; Pantouvakis, 2006; Dahl, Fenstad, \& Kongsvik, 2014; Field, 2009). In addition, items were also checked for their

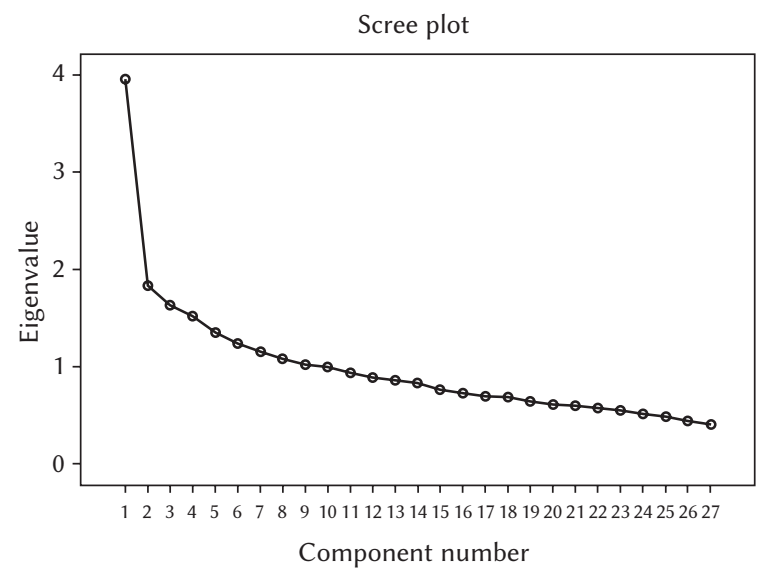

Figure 1. Scree plot for SD3, obtained through EFA $(N=379)$.

Table 3

Item loadings for all 27 items $(N=379)$

\begin{tabular}{|c|c|c|c|c|c|c|c|c|c|c|c|}
\hline \multirow[t]{2}{*}{ Items } & \multicolumn{3}{|c|}{ Factor } & \multirow[t]{2}{*}{ Items } & \multicolumn{3}{|c|}{ Factor } & \multirow[t]{2}{*}{ Items } & \multicolumn{3}{|c|}{ Factor } \\
\hline & 1 & 2 & 3 & & 1 & 2 & 3 & & 1 & 2 & 3 \\
\hline Mach1 & -.003 & -.023 & -.080 & Nar1 & -.122 & .623 & -.056 & Psy1 & .516 & .109 & -.157 \\
\hline Mach2 & .398 & -.013 & .111 & Nar2 & .052 & -.113 & -.065 & Psy2 & -.107 & -.075 & .555 \\
\hline Mach3 & .429 & .094 & .193 & Nar3 & .026 & .519 & -.094 & Psy3 & .539 & -.038 & .049 \\
\hline Mach4 & .225 & .069 & .268 & Nar4 & .030 & .577 & .022 & Psy4 & .443 & .006 & -.138 \\
\hline Mach5 & .597 & -.053 & -.093 & Nar5 & .001 & .383 & .262 & Psy5 & .392 & -.198 & .163 \\
\hline Mach6 & .518 & -.067 & -.092 & Nar6 & -.022 & -.054 & -.064 & Psy6 & .356 & .138 & -.035 \\
\hline Mach7 & .144 & .017 & .160 & Nar7 & -.005 & .483 & -.023 & Psy7 & -.141 & -.037 & .384 \\
\hline Mach8 & .399 & .043 & .030 & Nar8 & .015 & -.035 & .055 & Psy8 & .412 & -.136 & .004 \\
\hline Mach9 & .143 & .081 & .080 & Nar9 & .100 & .165 & .337 & Psy9 & .512 & .033 & -.008 \\
\hline
\end{tabular}

Note. Extraction method: principle axis factoring; rotation method: Promax with Kaiser normalization. 
Table 4

Items loading on the three factors $(N=379)$

\begin{tabular}{lccc}
\hline Items & \multicolumn{3}{c}{ Factors } \\
\cline { 2 - 3 } Mach5 & 1 & 2 & 3 \\
\hline Psy3 & .597 & \\
Mach6 & .539 & \\
Psy1 & .518 & \\
Psy9 & .516 & \\
Psy4 & .512 & \\
Mach3 & .443 & \\
Psy8 & .429 & \\
Narc1 & .412 & .623 \\
Narc4 & & .577 \\
Narc3 & & .519 \\
Narc7 & & .483 \\
Psy2 & & \\
\hline Ne.Extacton & & \\
\hline
\end{tabular}

Note. Extraction method: principal axis factoring; rotation method: Promax with Kaiser normalization.

respective impact on the cumulative scale reliability $(\alpha=.70)$. For each item, the value of Cronbach's $\alpha$ if item deleted (SPSS) was checked and items that impinged upon the overall reliability were dropped.

A total of 14 items were deleted in this process (Appendix 1) and eventually a 13-item matrix (Table 4) was generated. To cross-check the output, EFA was run a third time with the threshold for factor loadings being reduced to 0.3 . This analysis also produced a very similar output and supported the obtained item distribution pattern. However, results based on the standard criterion of 0.4 (Kerlinger, 1979) have been used in the current study.

\section{RESULTS}

EFA findings (Table 4) indicate that there are potential overlaps between Machiavellianism and psychopathy as items measuring the two constructs have loaded on the same factor. Narcissism, however, has loaded on a distinct factor. These findings are consistent with previous research outcomes (Rogoza \& Cieciuch, 2017; Persson et al., 2017). Moreover, only one reverse coded item (Psy2) loaded significantly on the third factor. This item showed an adverse impact on the overall reliability of the scale ( $\alpha$ if item deleted $=.71$ ). There is evidence to suggest that reverse-scored items often cluster into a separate factor instead of loading on their parent construct (Lyyra, Tormakangas, Read,
Rantanen, \& Berg, 2006; Long-Foley, Reed, Mutran, $\&$ DeVellis, 2002) and may produce unexpected factor structures (Netemeyer, Bearden, \& Sharma, 2003). Thus, the third factor was not included in further analysis as single item factors are not ideal for further analysis (MacCallum, Widaman, Zhang, \& Hong, 1999; Field, 2013). Based on these results only two factors with a total of 12 items qualified for further analysis. Considering the structural similarities between the emergent model and the one previously obtained by Rogoza and Cieciuch (2017), the same nomenclature is applied to denote the two factors (i.e. dark dyad to represent both Machiavellianism and psychopathy and narcissism as a separate construct).

\section{STUDY 2}

The purpose of study 2 was to confirm the factor structure that emerged in study 1 . With this aim, a confirmatory bifactor model was tested using Mplus-6.

\section{METHOD}

Study 2 was carried out on a separate dataset comprising $N=414$ observations. Participants included both male $(n=250)$ and female $(n=164)$ college students from the National Capital Region of Delhi, India. The age range of participants was 18 to 22 years with an average age of 21.2 years.

\section{MEASUREMENT}

The 12 items from the original SD3, that were retained in study 1 , were used for data collection in study 2 .

\section{PRELIMINARY DATA ANALYSIS}

No missing values or outliers were found in the dataset but it did lack normality. However, it has no effect on the outcome because Mplus has non-normality robust techniques such as MLR and MLM etc. which provide statistically adequate fit values even with non-normal data.

\section{RESULTS}

A confirmatory bifactor analysis (CBA) in Mplus-6 was conducted wherein all 12 items were simultaneously loaded on a single construct (dark personality) and two factors (dark dyad and narcissism) to ascertain dimensionality. As mentioned earlier, CBA enables researchers to test the dimensionality of tools (Hyland, 2005) and produces several fit indices, which are used in this study to estimate the goodness of model. 
Table 5

Values of model fit parameters

\begin{tabular}{lcccccccc}
\hline & $\chi^{2}$ & $d f$ & $p$ & $\chi^{2} / d f$ & CFI & TLI & SRMR & RMSEA \\
\hline $\begin{array}{l}\text { Sample }(N=414) \\
\begin{array}{l}\text { Confirmatory bifactor analysis } \\
\text { with two factors }\end{array}\end{array}$ & 147.84 & 42 & $<.001$ & 3.52 & 0.80 & 0.69 & 0.049 & 0.078 \\
\hline
\end{tabular}

Note. CFI - comparative fit index; TLI - Tucker-Lewis index; SRMR - standardized root mean square residual; RMSEA - root mean square error of approximation.

As can be seen in Table 5 some of the fit indices were in the acceptable range, as prescribed by researchers (Byrne, 1998; MacCallum, Browne, \& Sugawara, 1996), and hence the obtained model was accepted for further analysis.

As shown in Table 6, all the items measuring Machiavellianism and psychopathy loaded more strongly on a general factor, viz. dark personality instead of dark dyad (as found in study 1), while those assessing narcissism showed larger factor loadings on a distinct dimension. To further ascertain dimensionality, explained common variance (ECV) was computed. $\mathrm{ECV}$ is defined as "the ratio of variance explained by the general factor divided by the variance explained by the general plus the group factors" (Reise, 2012, p. 9). In the current study, ECVs for the two factors, viz. narcissism and dark dyad, were found to be 0.17 and 0.79 respectively. There is no benchmark to determine which value should be considered large enough to assume unidimensionality; however, ECV values that are closer to 1 are indicative of unidimensionality as they suggest that there is substantial common variance between the general construct and a particular factor. Therefore, the obtained ECV values strengthen our findings and suggest that while narcissism does not share enough common variance with the general negative personality disposition, dark dyad does. It translates into the idea that dark dyad overlaps more with a general negative propensity as compared to narcissism (as measured by SD3).

These results are contrary to previous research findings obtained by Moshagen et al. (2018) who demonstrated that all dark traits, including narcissism, are specific manifestations of a general common core of dark personality (D). CBA output indicates that Machiavellianism and psychopathy are better measured as manifestations of a general negative personality disposition. However, narcissism, as measured by SD3, does not converge with the general dark core of personality.

As can be seen in Table 7, the composite reliability (CR) of dark personality is greater than 0.6 , which indicates adequate internal consistency (Bagozzi \& Yi, 1988; Arnhold, 2010). However, on dark dyad and narcissism the values have turned out to be extremely low, indicating their lack of satisfactory internal con-
Table 6

Item loadings on dark personality as a general negative personality disposition and the two dimensions

\begin{tabular}{lcc}
\hline \multirow{2}{*}{ Items } & \multicolumn{2}{c}{ Factor loadings } \\
\cline { 2 - 3 } Mach3 & Dark personality & Dark dyad \\
Mach5 & $\mathbf{0 . 4 7 0}$ & 0.009 \\
Mach6 & $\mathbf{0 . 6 4 9}$ & -0.121 \\
Psy1 & $\mathbf{0 . 5 8 2}$ & -0.263 \\
Psy3 & $\mathbf{0 . 4 3 2}$ & 0.260 \\
Psy4 & $\mathbf{0 . 5 0 5}$ & 0.155 \\
Psy8 & $\mathbf{0 . 4 3 7}$ & 0.223 \\
Psy9 & 0.296 & 0.376 \\
Narc1 & $\mathbf{0 . 4 9 3}$ & 0.378 \\
Narc3 & & Narcissism \\
Narc4 & 0.159 & $\mathbf{0 . 4 9 8}$ \\
Narc7 & 0.258 & $\mathbf{0 . 3 9 3}$ \\
\hline NotVales & 0.220 & $\mathbf{0 . 3 4 5}$ \\
\hline
\end{tabular}

Note. Values in bold signify larger loadings.

sistency. The AVE values were found to be smaller than 0.5 , which signifies that all three latent variables have extremely low convergent validity (Urbach \& Ahlemann, 2010). Further, the Fornell-Larker criterion revealed that two of the three latent variables, viz. dark personality and narcissism, possess satisfactory divergent validity while dark dyad lacked this form of validity. Thus, the findings of study 2 produced a twofactor model, comprising (a) Machiavellianism and psychopathy and (b) narcissism. The results further indicated that Machiavellianism and psychopathy are closer to the dark core of personality than narcissism.

\section{STUDY 3}

In order to validate the results of studies 1 and 2 and to check the external validity of the emerging structure 
Table 7

Reliability and convergent/divergent validity of the bifactor model

\begin{tabular}{lccccc}
\hline & CR & AVE & Dark personality & Dark dyad & Narcissism \\
\hline Dark personality & 0.68 & 0.18 & $\mathbf{0 . 4 2}$ & & \\
Dark dyad & 0.12 & 0.06 & 0.30 & $\mathbf{0 . 2 4}$ & 0.41 \\
Narcissism & 0.46 & 0.18 & 0.27 & $\mathbf{0 . 4 2}$ \\
\hline
\end{tabular}

Note. CR - composite reliability; AVE - average variance extracted; square root of AVE along the diagonal.

of SD3, a third study was conducted. For this purpose, dark dyad and narcissism were separately examined in relation to certain behavioral and inter-personal characteristics that have been previously associated with dark personality traits. All three dark traits have been linked to greater social dominance orientation (Hodson, Hogg, \& MacInnis, 2009). They have been found to share a common core of callousness (Jones \& Paulhus, 2011) and lack of empathy (Jones \& Neria, 2015). However, narcissists have been reported as being relatively more empathetic (Heym et al., 2019) and less callous (Miller et al., 2017) than both Machiavellians and psychopaths. There is also evidence that the three dark traits manifest moral deficits (Arvan, 2013; Bartels \& Pizarro, 2011; Campbell et al., 2009); however, psychopaths as well as Machiavellians are considered morally more corrupt than narcissists (Glenn, Iyer, Graham, Koleva, \& Haidt, 2009).

Therefore, it is proposed that dark dyad traits (Machiavellianism and psychopathy) would correlate more strongly with social dominance and callousness as they share more closeness with the general core of dark personality (Egan, Chan, \& Shorter, 2014) than narcissism. Similarly, dark dyad would correlate more negatively with morality and empathy than narcissism. It is also proposed that dark dyad would predict social dominance and callousness more strongly than narcissism, whereas morality and empathy would be predicted in the opposite direction.

\section{METHOD}

The sample of study 3 comprised $N=168$ participants from National Capital region of Delhi, India, out of which $n=131$ were female and $n=37$ were male. Participants' ages ranged from 17 to 35 years with a mean age of 20.41 years.

\section{MEASUREMENT}

Social Dominance Orientation Scale. For the assessment of social dominance, the Social Dominance Orientation Scale $\left(\mathrm{SDO}_{7}\right.$ ) by Ho et al. (2015) was used. The tool has 16 items that are rated on a seven-point scale. High scores on the scale indicate greater social dominance orientation. The tool has previously been found to be reliable and valid (Ho et al., 2015). On the current sample, it showed a Cronbach's $\alpha$ of .82 .

Moral Foundations Sacredness Scale. The Moral Foundations Sacredness Scale by Graham and Haidt (2012) was used to measure morality. The scale has 20 items that are to be rated on an eight-point scale. It has shown satisfactory reliability and validity (Vecina, 2014). It showed satisfactory reliability (Cronbach's $\alpha=.77$ ) on the current sample.

Inventory of Callous-Unemotional Traits. Callous traits were measured using the Inventory of CallousUnemotional Traits - youth version (Frick, 2004). It has 24 items that are rated on a 4-point scale. Although the youth version is meant for adolescents (13-17 years) it has been used on an adult population as well (Byrd, Kahn, \& Pardini, 2013). The tool has been found to possess sufficient psychometric properties (Roose, Bijttebier, Decoene, Claes, \& Frick, 2010). Cronbach's $\alpha$ for the tool on the current sample was found to be .71 .

Toronto Empathy Questionnaire. The Toronto Empathy Questionnaire (Spreng, McKinnon, Mar, \& Levine, 2009) was used to measure empathy. The tool employs a five-point scale and has sufficient reliability and validity (Spreng et al., 2009). On the present sample, it showed an $\alpha$ reliability of .75 .

Dark dyad and narcissism were measured using the 12 items of the SD3 scale as found more valid in studies 1 and 2. Cronbach's $\alpha$ were found to be .65 and .70 respectively on the current sample.

\section{RESULTS}

Table 8 indicates that dark dyad correlated positively with social dominance orientation $(r=.34, p<.01)$ and negatively with both morality $(r=-.21, p<.01)$ and empathy $(r=-.22, p<.01)$. On the other hand, narcissism did not correlate significantly with social dominance orientation. Narcissism showed positive correlations with both morality $(r=.01)$ and empathy $(r=.04)$, although correlations were very low. Callousness did not correlate significantly with either dark dyad or narcissism. However, it showed low pos- 
Table 8

Pearson's correlation coefficients

\begin{tabular}{|c|c|c|c|c|c|}
\hline & SD & M & $\mathrm{CT}$ & $\mathrm{E}$ & DD \\
\hline Social dominance (SD) & 1 & & & & \\
\hline Morality (M) & -.12 & 1 & & & \\
\hline Callous traits $(\mathrm{CT})$ & .14 & $-.26^{* *}$ & 1 & & \\
\hline Empathy (E) & $-.30 * *$ & $.27^{* *}$ & $-.55^{* *}$ & 1 & \\
\hline Dark dyad (DD) & $.34^{* *}$ & $-.21^{* *}$ & .10 & $-.22^{* *}$ & 1 \\
\hline Narcissism $(\mathrm{N})$ & .10 & .01 & -.03 & .04 & $.23^{* *}$ \\
\hline
\end{tabular}

Table 9

Regression coefficients

\begin{tabular}{|c|c|c|c|c|c|c|c|c|c|c|c|c|}
\hline \multirow{2}{*}{$\frac{\text { Predictors }}{\text { Dark dyad }}$} & \multicolumn{3}{|c|}{ Social dominance } & \multicolumn{3}{|c|}{ Morality } & \multicolumn{3}{|c|}{ Callousness } & \multicolumn{3}{|c|}{ Empathy } \\
\hline & \multirow{2}{*}{$\begin{array}{l}R^{2} \\
.11 \\
\end{array}$} & \multicolumn{2}{|r|}{$F$} & $R^{2}$ & \multicolumn{2}{|r|}{$F$} & $R^{2}$ & \multicolumn{2}{|c|}{$F$} & $R^{2}$ & \multicolumn{2}{|c|}{$F$} \\
\hline & & \multicolumn{2}{|c|}{21.64} & .04 & \multicolumn{2}{|c|}{7.88} & .01 & \multicolumn{2}{|c|}{1.58} & .04 & \multicolumn{2}{|c|}{8.28} \\
\hline & $\beta$ & $t$ & $p$ & $\beta$ & $t$ & $p$ & $\beta$ & $t$ & $p$ & $\beta$ & $t$ & $p$ \\
\hline & .34 & 4.65 & $<.001^{* *}$ & -.21 & 2.80 & $.006^{* *}$ & .10 & 1.25 & .211 & -.22 & 2.87 & $.005^{* *}$ \\
\hline \multirow[t]{4}{*}{ Narcissism } & $R^{2}$ & \multicolumn{2}{|r|}{$F$} & $R^{2}$ & \multicolumn{2}{|r|}{$F$} & $R^{2}$ & \multicolumn{2}{|c|}{$F$} & $R^{2}$ & \multicolumn{2}{|c|}{$F$} \\
\hline & .01 & & 1.56 & .00 & \multicolumn{2}{|c|}{0.01} & .00 & \multicolumn{2}{|c|}{0.14} & .00 & \multicolumn{2}{|c|}{0.24} \\
\hline & $\beta$ & $t$ & $p$ & $\beta$ & $t$ & $p$ & $\beta$ & $t$ & $p$ & $\beta$ & $t$ & $p$ \\
\hline & .10 & 1.24 & .213 & .01 & 0.07 & .937 & -.03 & 0.37 & .709 & .03 & 0.49 & .623 \\
\hline
\end{tabular}

itive and low negative correlations respectively with them. Finally, the correlation between narcissism and dark dyad was found to be $.23(p<.01)$ suggesting that these traits are moderately related to each other.

In addition, linear regression analyses were run to check how dark dyad predicted social dominance, callousness, morality and empathy vis-à-vis narcissism.

As shown in Table 9, dark dyad was found to be a significant positive predictor of social dominance $\left(R^{2}=.11, \beta=.34, t(167)=4.65, p<.01\right)$ and a significant negative predictor of morality $\left(R^{2}=.04, \beta=-.21\right.$, $t(167)=2.80, p<.01)$ as well as empathy $\left(R^{2}=.04\right.$, $\beta=-.22, t(167)=2.87, p<.01)$. However, narcissism failed to predict any of these criterion variables significantly.

\section{DISCUSSION}

The present research aimed to explore the construct validity of SD3 by conducting three independent studies. Exploratory factor analysis in study 1 produced a two-factor model with 12 items. The first factor, viz. dark dyad, includes items of Machiavellian- ism and psychopathy and the other factor comprises items measuring narcissism. The two-factor conceptualization has been supported in some previous studies as well (Persson et al., 2017; Rogoza \& Cieciuch, 2017). However, results of study 2 demonstrated that Machiavellianism and psychopathy are better measured as manifestations of a general dark core of personality rather than as a unitary dimension (dark dyad). This finding is in line with previous research which indicated that psychopathy and Machiavellianism are more central to the dark core of personality (Egan et al., 2014; Kajonius et al., 2016) as they exhibit greater overlap with other anti-social behaviors such as moral disengagement, unethical attitudes, and disagreeableness, etc. (Egan, Hughes, \& Palmer, 2015; Muris, Merckelbach, Otgaar, \& Meijer, 2017).

Narcissism, as measured by SD3, emerged as a distinct dimension which does not necessarily reflect the general dark core of personality. There is evidence suggesting that narcissism is not always negative (Campbell, 2001) and therefore may not load on the general negative disposition of dark personality. Campbell (2001) opined that "narcissism may be a functional and healthy strategy for dealing with 
the modern world" (p. 215). Sudha and Shahnawaz (in press) found that narcissism can predict desirable organizational outcomes if the context is favorable. Similarly, Paulhus, Williams, and Harms (2001) empirically demonstrated that narcissism per se is not a dangerous trait but how it interacts with other negative factors (such as aggression) determines how toxic and socially aversive it can become. Heym et al. (2019) also found that narcissism is not problematic or dangerous as long as the other two traits (psychopathy and Machiavellianism) are not present in a person. Their research further indicated that traits of psychopathy and Machiavellianism are characterized by empathetic deficits but narcissism stands out as people with this trait do have some amount of empathy. Machiavellianism and psychopathy were found to be more strongly associated with lack of moral concerns than narcissism (Arvan, 2013). Hence Machiavellianism and psychopathy are often considered more negative or "darker" personality traits (ZeigerHill \& Marcus, 2016, p. 6) than narcissism. Another reason the general dark core of personality could not explain narcissism significantly is because the form of narcissism that SD3 measures does not cover the hostile side of the construct. Moshagen, Zettler, and Hilbig (2020) have reported that narcissism converges better with the general dark core when it is assessed with an emphasis on the antagonistic side.

The results further showed that dark personality as a general construct possesses acceptable composite reliability in contrast to dark dyad and narcissism. Moreover, the average variance explained (AVE) for dark personality, dark dyad, and narcissism were found to be $0.18,0.06$, and 0.18 respectively, which suggests that the items are not measuring their respective latent variables effectively (Hair et al., 2010). This may be because of the intrinsic dimensionality (Appendix 2) of these factors (Jones \& Paulhus, 2014) which goes untapped when cumulative scores are computed. These findings align with the observation made by Miller, Vize, Crowe, and Lynam (2019), who asserted that: "Failure to appreciate the multidimensionality of these constructs can lead to inadequate measurement and less coherent theoretical models. Reliance on total scores also obscures substantial differences among the components within each construct" (p. 6).

Furthermore, dark personality (as a core construct) and the dimension of narcissism meet the Fornell-Larker criterion, which lends support for their adequate divergent validity. It implies that both these latent constructs are exclusive and do not overlap with one another. Dark dyad, however, exhibits poor divergence owing to its conspicuous overlap with the dark core of personality. This finding further provides support for the conclusion that narcissism is a distinct trait that does not overlap with dark personality or dark dyad.
To examine the external validity of results obtained in study 2, study 3 was carried out employing correlation and linear regression analyses. Dark dyad was found to have a positive and significant correlation with social dominance orientation, but showed negative associations with morality and empathy. This is similar to what has been reported by Arvan (2013) and Heym et al. (2019), respectively. On the other hand, narcissism showed a non-significant yet positive correlation with morality and empathy, which suggests that narcissists are less devoid of these positive traits than those characterized by dark dyad traits (Miller et al., 2017). Likewise, scores on narcissism correlated negatively with callousness. Despite its statistical insignificance, the correlation coefficient clearly indicated that narcissists are lower on callousness than their dark dyadic counterparts (Miller et al., 2017). Further, in regression analyses, dark dyad predicted scores on social dominance positively while morality and empathy were predicted by the construct negatively. Narcissism, on the other hand, did not significantly predict any of these variables.

Therefore, based on the findings of the three studies, it was concluded that SD3 does not converge with the originally conceived three factor structure. Moreover, the results consistently indicated that unlike dark dyad, narcissism (as measured by SD3) does not chime with the dark core of personality given its relative proximity with positive and socially desirable traits such empathy and morality. Put simply, Machiavellianism and psychopathy seem to overlap to the extent that they can be subsumed into one construct, viz. dark dyad, which is more central to the dark core of personality. Conversely, narcissism, as per SD3, seems less negative as compared to dark dyad since it does not share a common core of moral and empathetic deficits and social dominance orientation, unlike the latter.

\section{CONCLUSIONS}

In the current research, one of the most widely employed measures of dark traits, viz. SD3, has been subjected to an exploratory factor analysis followed by a confirmatory bifactor analysis, in a non-Western context. The results indicate that the tool does not conform to the original three-factor model and produces a two-factor structure with items tapping Machiavellianism and psychopathy loading on one factor while those assessing narcissism constitute a separate factor. Furthermore, Machiavellianism and psychopathy emerge as manifestations of a general negative propensity while narcissism does not follow this pattern, which suggests that narcissism (as measured by SD3) is not necessarily a negative personality trait. This is further supported by correlation and regression analyses (study 3 ) which showed 
that dark dyad is a better correlate and predictor of other negative constructs as compared to narcissism. Therefore, one should be careful when using SD3 in its original from as it does not measure the factor structure as claimed by the authors.

\section{ENDNOTE}

1 Crossref: 353; Web of Science: 306; ResearchGate: 482.

\section{RefERENCES}

Arnhold, U. (2010). User-generated branding - Integrating user-generated content into brand management. Wiesbaden: Gabler Verlag.

Arvan, M. (2013). A lot more bad news for conservatives, and a little bit of bad news for liberals? Moral judgments and the dark triad personality traits: a follow-up study. Neuroethics, 6, 51-64. https:// doi.org/10.1007/s12152-012-9155-7

Atari, M., \& Chegeni, R. (2016). Assessment of dark personalities in Iran: Psychometric evaluation of the Farsi translation of the Short Dark Triad (SD3-F). Personality and Individual Differences, 102, 111-117. https://doi.org/10.1016/j.paid.2016.06.070

Bagozzi, R. P., \& Yi, Y. (1988). On the evaluation of structural equation models. Journal of the Academy of Marketing Science, 16, 74-94. https://doi. org/10.1007/BF02723327

Bartels, D. M., \& Pizarro, D. A. (2011). The mismeasure of morals: Antisocial personality traits predict utilitarian responses to moral dilemmas. Cognition, 121, 154-161. https://doi.org/10.1016/j. cognition.2011.05.010

Byrd, A. L., Kahn, R. E., \& Pardini, D. A. (2013). A validation of the inventory of callous-unemotional traits in a community sample of young adult males. Journal of Psychopathology and Behavioral Assessment, 35, 20-34. https://doi.org/10.1007/s10862-012-9315-4

Byrne, B. M. (1998). Structural equation modeling with LISREL, PRELIS, and SIMPLIS: Basic concepts, applications, and programming. Mahwah, NJ: Lawrence Erlbaum Associates.

Campbell, W. K. (2001). Is narcissism really so bad? Psychological Inquiry, 12, 214-216.

Campbell, J., Schermer, J. A., Villani, V. C., Nguyen, B., Vickers, L., \& Vernon, P. A. (2009). A behavioral genetic study of the dark triad of personality and moral development. Twin Research and $\mathrm{Hu}$ man Genetics, 12, 132-136. https://doi.org/10.1375/ twin.12.2.132

Carter, G. L., Campbell, A., \& Muncer, S. (2013). The Dark Triad personality: Attractiveness to women. Personality and Individual Differences, 56, 57-61. https://doi.org/10.1016/j.paid.2013.08.021
Cerit, A. G. (2000). Maritime transport as an area of competitive advantage in international marketing. International Journal of Maritime Economics, 2, 49-67. https://doi.org/10.1057/ijme.2000.6

Crowe, M. L., Lynam, D. R., Campbell, W. K., \& Miller, J. D. (2019). Exploring the structure of narcissism: Toward an integrated solution. Journal of Personality, 87, 1151-1169. https://doi.org/10.1111/jopy.12464

Czarna, A. Z., Jonason, P. K., Dufner, M., \& Kossowska, M. (2016). The Dirty Dozen scale: Validation of a Polish version and extension of the nomological net. Frontiers in Psychology, 7, 445. https://doi. org/10.3389/fpsyg.2016.00445

Dahl, Ø., Fenstad, J., \& Kongsvik, T. (2014). Antecedents of safety-compliant behaviour on offshore service vessels: a multi-factorial approach. Maritime Policy \& Management, 41, 20-41. https://doi. org/10.1080/03088839.2013.780311

Egan, V., Chan, S., \& Shorter, G. W. (2014). The Dark Triad, happiness and subjective well-being. Personality and Individual Differences, 67, 17-22. https://doi.org/10.1016/j.paid.2014.01.004

Egan, V., Hughes, N., \& Palmer, E. J. (2015). Moral disengagement, the dark triad, and unethical consumer attitudes. Personality and Individual Differences, 76, 123-128. https://doi.org/10.1016/j.paid.2014.11.054

Field, A. (2009). Discovering statistics using SPSS (3 $3^{\text {rd }}$ ed.). London: Sage Publications.

Field, A. (2013). Discovering statistics using IBM SPSS Statistics ( $4^{\text {th }}$ ed.). Los Angeles, CA: Sage.

Frick, P. J. (2004). Inventory of callous-unemotional traits (Unpublished rating scale). University of New Orleans. Retrieved from https://sites01.Isu.edu/ faculty/pfricklab/wp-content/uploads/sites/100/ 2015/11/ICU-Youth.pdf

Furtner, M., Maran, T. K., \& Rauthmann, J. F. (2017). Dark leadership: The role of leaders' dark triad personality traits. In M. G. Clark \& C. W. Gruber (Eds.), Annals of theoretical psychology, Vol. 15. Leader development deconstructed (pp. 75-99). Switzerland: Springer.

Gamache, D., Savard, C., \& Maheux-Caron, V. (2017). French adaptation of the Short Dark Triad: Psychometric properties and a head-to-head comparison with the Dirty Dozen. Personality and Individual Differences, 122, 164-170. https://doi.org/10.1016/j. paid.2017.10.027

Glenn, A. L., lyer, R., Graham, J., Koleva, S., \& Haidt, J. (2009). Are all types of morality compromised in psychopathy? Journal of Personality Disorders, 23, 384-398. https://doi.org/10.1521/pedi.2009.23.4.384

Graham, J., \& Haidt, J. (2012). Sacred values and evil adversaries: a moral foundations approach. In M. Mikulincer \& P. R. Shaver (Eds.), Herzliya series on personality and social psychology. The social psychology of morality: Exploring the causes of good and evil (pp. 11-31). Washington, DC: American Psychological Association. 
Hair, J. F., Black, W. C., Babin, B. J., \& Anderson, R. E. (2010). Multivariate data analysis ( $7^{\text {th }}$ ed.). Upper Saddle River, NJ: Prentice-Hall, Inc.

Heym, N., Firth, N., Kibowski, F., Sumich, A., Egan, V., \& Bloxsom, C. A. J. (2019). Empathy at the heart of darkness: Empathy deficits that bind the dark triad and those that mediate indirect relational aggression. Frontiers in Psychiatry, 10, 95. https:// doi.org/10.3389/fpsyt.2019.00095

Ho, A. K., Sidanius, J., Kteily, N., Sheehy-Skeffington, J., Pratto, F., Henkel, K. E., Foels, R., \& Stewart, A. L. (2015). The nature of social dominance orientation: Theorizing and measuring preferences for intergroup inequality using the new $\mathrm{SDO}_{7}$ scale. Journal of Personality and Social Psychology, 109, 1003-1028. https://doi.org /10.1037/pspi0000033

Hodson, G., Hogg, S. M., \& Maclnnis, C. C. (2009). The role of "dark personalities" (narcissism, Machiavellianism, psychopathy), Big Five personality factors, and ideology in explaining prejudice. Journal of Research in Personality, 43, 686-690. https://doi. org/10.1016/j.jrp.2009.02.005

Hyland, P. (2015). Application of bifactor models in criminal psychology research: a guide to researchers. Journal of Criminal Psychology, 5, 65-74. https:// doi.org/10.1108/JCP-03-2015-0011

Jonason, P. K. (2014). Personality and politics. Personality and Individual Differences, 71, 181-184. https:// doi.org/10.1016/j.paid.2014.08.002

Jonason, P. K., \& Kavanagh, P. (2010). The dark side of love: Love styles and the Dark Triad. Personality and Individual Differences, 49, 606-610. https://doi. org/10.1016/j.paid.2010.05.030

Jonason, P. K., Li, N. P., \& Buss, D. M. (2010). The costs and benefits of the Dark Triad: Implications for mate poaching and mate retention tactics. Personality and Individual Differences, 48, 373-378. https://doi.org/10.1016/j.paid.2009.11.003

Jonason, P. K., Li, N. P., Webster, G. D., \& Schmitt, D. P. (2009). The Dark Triad: Facilitating a short-term mating strategy in men. European Journal of Personality, 23, 5-18. https://doi.org/10.1002/per.698

Jonason, P. K., \& Webster, G. D. (2010). The dirty dozen: a concise measure of the dark triad. Psychological Assessment, 22, 420-432. https://doi.org/10.1037/ a0019265

Jones, D. N., \& Figueredo, A. J. (2013). The core of darkness: Uncovering the heart of the dark triad. European Journal of Personality, 27, 521-553. https://doi. org/10.1002/per.1893

Jones, D. N. \& Neria, A. L. (2015). The Dark Triad and dispositional aggression. Personality and Individual Differences, 86, 360-364. https://doi.org/10.1016/j. paid.2015.06.021

Jones, D. N., \& Paulhus, D. L. (2011). Differentiating the Dark Triad within the interpersonal circumplex. In L. M. Horowitz \& S. Strack (Eds.), Handbook of interpersonal psychology: Theory, research, assess- ment, and therapeutic interventions (pp. 249-268). New York: Wiley.

Jones, D. N., \& Paulhus, D. L. (2014). Introducing the Short Dark Triad (SD3): a brief measure of dark personality traits. Assessment, 21, 28-41. https:// doi.org/10.1177/1073191113514105

Kajonius, P. J., Persson, B. N., Rosenberg, P., \& Garcia, D. (2016). The (mis)measurement of the Dark Triad Dirty Dozen: Exploitation at the core of the scale. PeerJ, 4, e1748. https://doi.org/10.7717/peerj.1748

Kerlinger, F. N. (1979). Behavioral research: a conceptual approach. New York: Holt, Rinehart, and Winston.

Kernberg, O. F. (1998). Pathological narcissism and narcissistic personality disorder: Theoretical background and diagnostic classification. In E. F. Ronningstam (Ed.), Disorders of narcissism: Diagnostic, clinical, and empirical implications (p. 29-51). Washington, DC: American Psychiatric Association.

Long-Foley, K., Reed, P. S., Mutran, E. J., \& DeVellis, R. F. (2002). Measurement adequacy of the CES-D among a sample of older African Americans. Psychiatry Research, 109, 61-69. https://doi. org/10.1016/S0165-1781(01)00360-2

Lyyra, T. M., Tormakangas, T. M., Read, S., Rantanen, T., \& Berg, S. (2006). Satisfaction with present life predicts survival in octogenarians. Journal of Gerontology: Series B, 61, 319-326. https://doi.org//10.1093/ geronb/61.6.P319

MacCallum, R. C., Browne, M. W., \& Sugawara, H. M. (1996). Power analysis and determination of sample size for covariance structure modeling. Psychological Methods, 1, 130-149. https://doi.org/10.1037/1082989X.1.2.130

MacCallum, R. C., Widaman, K., Zhang, S., \& Hong, S. (1999). Sample size in factor analysis. Psychological Methods, 4, 84-99. https://doi.org/10.1037/1082989X.4.1.84

Maharana, S. S. (2019). Antagonism and dark triad (core): a facet level examination. PsyArXiv Preprints. https://doi.org/10.31234/osf.io/3jfc4

Malesza, M., Ostaszewski, P., Büchner, S., \& Kaczmarek, M. C. (2019). The adaptation of the Short Dark Triad personality measure: Psychometric properties of a German sample. Current Psychology, 38, 855-864. https://doi.org/10.1007/s12144-017-9662-0

Maples, J. L., Lamkin, J., \& Miller, J. D. (2014). A test of two brief measures of the dark triad: The dirty dozen and the short dark triad. Psychological Assessment, 26, 326-331. https://doi.org/10.1037/a0035084

Maskey, R., Fei, J., \& Nguyen, H. (2018). Use of exploratory factor analysis in maritime research. The Asian Journal of Shipping and Logistics, 34, 91-111. https://doi.org/10.1016/j.ajsl.2018.06.006

Miller, J. D., Hyatt, C. S., Maples-Keller, J. L., Carter, N. T., \& Lynam, D. R. (2017). Psychopathy and Machiavellianism: a distinction without a difference? Journal of Personality, 85, 439-453. https://doi.org/10.1111/ jopy. 12251 
Miller, J., Vize, C., Crowe, M., \& Lynam, D. (2019). A critical appraisal of the Dark Triad literature and suggestions for moving forward. Current Directions in Psychological Science, 28, 353-360. https:// doi.org/10.1177/0963721419838233

Moshagen, M., Hilbig, B., \& Zettler, I. (2018). The dark core of personality. Psychological Review, 125, 656688. https://doi.org 10.1037/rev0000111

Moshagen, M., Zettler, I., \& Hilbig, B. E. (2020). Measuring the dark core of personality. Psychological Assessment, 32, 182-196. https://doi.org/10.1037/ pas0000778

Muris, P., Merckelbach, H., Otgaar, H., \& Meijer, E. (2017). The malevolent side of human nature: a meta-analysis and critical review of the literature on the dark triad (narcissism, Machiavellianism, and psychopathy). Perspectives on Psychological Science, 12, 183-204. https://doi.org/10.1177/1745691616666070

Netemeyer, R. G., Bearden, W. O., \& Sharma, S. (2003). Scaling procedures: Issues and applications. Newbury Park, CA: Sage Publications.

Özsoy, E., Rauthmann, J. F., Jonason, P. K., \& Ardıç, K. (2017). Reliability and validity of the Turkish versions of Dark Triad Dirty Dozen (DTDD-T), Short Dark Triad (SD3-T), and Single Item Narcissism Scale (SINS-T). Personality and Individual Differences, 117, 11-14. https://doi.org/10.1016/j.paid.2017.05.019

Pantouvakis, A. (2006). Port-service quality dimensions and passenger profiles: an exploratory examination and analysis. Maritime Economics \& Logistics, 8, 402-418. https://doi.org/10.1057/palgrave. mel.9100167

Paulhus, D. L., \& Williams, K. M. (2002). The dark triad of personality: Narcissism, Machiavellianism, and psychopathy. Journal of Research in Personality, 36, 556-563. https://doi.org/10.1016/S00926566(02)00505-6

Paulhus, D. L., Williams, K., \& Harms, P. (2001). Shedding light on the Dark Triad of personality: Narcissism, Machiavellianism, and psychopathy. Paper presented at Society for Personality and Social Psychology Convention, San Antonio. Retrieved from https://www2.psych.ubc.ca/ dpaulhus/research/ DARK_TRIAD/PRESENTATIONS/sheddinglightspsp01poster.pdf

Pechorro, P., Caramelo, V., Oliveira, J. P., Nunes, C., Curtis, S. R., \& Jones, D. E. N. (2019). The Short Dark Triad (SD3): Adaptation and psychometrics among at-risk male and female youths. Deviant Behavior, 40, 273-286. https://doi.org/10.1080/01639625.2017. 1421120

Persson, B. N., Kajonius, P. J., \& Garcia, D. (2017). Revisiting the structure of the Short DarkTriad. Assessment, 26, 3-16. https://doi.org/10.1177/1073191117701192

Pincus, A. L., \& Lukowitsky, M. R. (2010). Pathological narcissism and narcissistic personality disorder. Annual Review of Clinical Psychology, 6, 421-446. https://doi.org/10.1146/annurev.clinpsy.121208.131215.
Reis, H. T., \& Judd, C. M. (2000). Handbook of research methods in social and personality psychology. Cambridge: Cambridge University Press.

Reise, S. P. (2012). The rediscovery of bifactor measurement models. Multivariate Behavioral Research, 47, 667-696. https://doi.org/10.1080/00273171.2012. 715555

Rogoza, R., \& Cieciuch, J. (2017). Structural investigation of the Short Dark Triad questionnaire in Polish population. Current Psychology, 38, 756-763. https://doi.org/10.1007/s12144-017-9653-1

Roose, A., Bijttebier, P., Decoene, S., Claes, L., \& Frick, P. J. (2010). Assessing the affective features of psychopathy in adolescence: a further validation of the Inventory of Callous and Unemotional Traits. Assessment, 17, 44-57. https://doi. org/10.1177/1073191109344153

Salessi, S., \& Omar, A. (2018). Psychometric properties of a scale to measure the dark side of personality. Estudos de Psicologia, 35, 159-170. https:// doi.org/10.1590/1982-02752018000200005

Sidanius, J., \& Pratto, F. (1999). Social dominance: an intergroup theory of social hierarchy and oppression. Cambridge: Cambridge University Press.

Spreng, R. N., McKinnon, M. C., Mar, R. A., \& Levine, B. (2009). The Toronto Empathy Questionnaire. Scale development and initial validation of a factor-analytic solution to multiple empathy measures. Journal of Personality Assessment, 91, 62-71. https://doi. org/10.1080/00223890802484381

Spurk, D., Keller, A. C., \& Hirschi, A. (2015). Do bad guys get ahead or fall behind? Relationships of the dark triad of personality with objective and subjective career success. Social Psychological and Personality Science, 7, 113-121. https://doi.org/10. 1177/1948550615609735

Sudha, K. S., \& Shahnawaz, M. G. (in press). Narcissism personality trait and performance: Task-oriented leadership and authoritarian styles as mediators. Leadership and Organization Development Journal. https://doi.org/10.1108/LODJ-09-2019-0399

Tabachnick, B. G., \& Fidell, L. S. (2007). Using multivariate statistics $\left(6^{\text {th }}\right.$ ed). Harlow: Pearson.

Urbach, N., \& Ahlemann, F. (2010). Structural equation modeling in information systems research using partial least squares. Journal of Information Technology Theory and Application, 11, 5-40.

Vecina, M. L. (2014). The Five Moral Foundations Sacredness Scale in men in court-mandated treatment for violently abusing their partners. Personality and Individual Differences, 64, 46-51. https:// doi.org/10.1016/j.paid.2014.02.021

Zeiger-Hill, V., \& Marcus, D. K. (2016). A bright future for dark personality features? In V. Zeigler-Hill \& D. K. Marcus (Eds.), The dark side of personality: Science and practice in social, personality, and clinical psychology (pp. 3-22). Washington, DC: American Psychological Association. 
APPENDIX 1

Reasons for item deletion in EFA

\begin{tabular}{lcc}
\hline Deleted items & $\begin{array}{c}\text { Factor loadings } \\
<0.4\end{array}$ & $\begin{array}{c}\text { Impinging scale } \\
\text { reliability }\end{array}$ \\
\hline Mach1 & $\checkmark$ & \\
Mach2 & $\checkmark$ & \\
Mach4 & $\checkmark$ & \\
Mach7 & $\checkmark$ & \\
Mach8 & $\checkmark$ & \\
Mach9 & $\checkmark$ & \\
Psy5 & $\checkmark$ & $\checkmark$ \\
Psy6 & $\checkmark$ & $\checkmark$ \\
Psy7 & $\checkmark$ & \\
Nar2 & $\checkmark$ & $\checkmark$ \\
Nar5 & $\checkmark$ & $\checkmark$ \\
Nar6 & $\checkmark$ & \\
Nar8 & $\checkmark$ & \\
Nar9 & $\checkmark$ & \\
& & \\
\hline
\end{tabular}

\section{APPENDIX 2}

Sub-dimensions of each factor in SD3

\begin{tabular}{lccc}
\hline Items & & Sub-dimensions & \\
\cline { 2 - 4 } & Machiavellianism & Narcissism & Psychopathy \\
\hline 1 & Reputation & Leadership & Antisocial behavior \\
3 & Manipulation & Exhibitionism & Erratic lifestyle \\
4 & Coalition building & Grandiosity & Callous affect \\
5 & Coalition building & Grandiosity & Erratic lifestyle \\
6 & Planning & Entitlement & Callous affect \\
7 & Planning & Exhibitionism & Antisocial behavior \\
8 & Reputation & Grandiosity & Antisocial behavior \\
9 & Planning & Grandiosity & Callous affect \\
\hline
\end{tabular}

Source: Jones and Paulhus (2013). 